\title{
Minute Times Millimole Per Liter Per Gram
}

National Cancer Institute

\section{Source}

National Cancer Institute. Minute Times Millimole Per Liter Per Gram. NCI Thesaurus.

Code C112344.

Minutes times millimoles per liter, divided by grams. 